\title{
MODEL VALUES OF MOTOR ABILITIES OF JUNIOR RHYTHMIC GYMNASTS IN THE REPUBLIC OF CROATIA
}

\author{
Josipa Radaš, Marita Ukić, and Gordana Furjan Mandić \\ University of Zagreb, Faculty of Kinesiology, Croatia
}

Original scientific paper

DOI: $10.26582 / \mathrm{k} .51 .2 .11$

\begin{abstract}
:
Knowing the current status of rhythmic gymnasts' motor abilities allows a valid objective evaluation of their competitive preparedness and facilitates planning of their further development. The main objective was to determine possible differences in motor abilities of rhythmic gymnasts regarding program level they were competing in, their biological age and national ranking. Three groups of junior rhythmic gymnasts, competing in either A, B, or C level programs, were investigated. Both the multivariate analysis of variance and univariate analysis of variance showed statistically significant differences in the selected motor abilities regarding the program. A-level rhythmic gymnasts scored best in all the tests assessing flexibility, coordination and strength. The differences in motor abilities among junior rhythmic gymnasts with regard to their national ranking showed no statistical significance, whereas biological age was statistically significant. The differences confirm that among Croatian junior rhythmic gymnasts aged 13-15, biologically advanced individuals showed a significant advantage compared to the ones that would enter puberty at a later age. The Pearson's correlation coefficient revealed significant relations between certain motor abilities among rhythmic gymnasts in A, $\mathrm{B}$ and $\mathrm{C}$ level programs. The higher the level of a program, the higher the correlatives, and vice versa. The scientific value of the proposed research is aimed at better planning, programming and control of training process in rhythmic gymnastics.
\end{abstract}

Key words: rhythmic gymnastics, program level, motor abilities

\section{Introduction}

To succeed in rhythmic gymnastics (RG), an athlete should perfect and coordinate a variety of motor skills and abilities to execute competitive choreography at the highest possible quality level. Well-developed motor capacities and skills enable adoption of RG elements, thus creating a broad base for the development of RG technical skills necessary for the execution of elements with and without apparatuses (Jastrjembskaia \& Titov,1999). It is assumed that almost all motor abilities of a gymnast need to be developed optimally to succeed in the sport as complex as rhythmic gymnastics, but it is not quite clear which motor abilities differentiate between age and standard groups, or programs. The majority of research on the classification and importance of motor abilities and skills in rhythmic gymnastics is focused on the differences in performance with apparatuses and, in recent times, on the differences between male and female athletes (Bozanic \& Miletic, 2011; Di Cagno, et al., 2009). Based on the review of previous studies on RG, we have noticed that there is a lack of studies that would investigate associations between gymnasts' motor skills and abilities with the participation in a particular program. The "A" program is designed and performed according to the regulations of the International Gymnastics Federation (FIG, 2017), also called the top program, and the best gymnasts participate in it. The " $\mathrm{B}$ " program is a program that is conducted according to the regulations of the Croatian Gymnastics Federation, and the competitions in this program embrace both the individual and group routines. The " $\mathrm{C}$ " program implementation at the national level began in 2008. In the "C" program, the emphasis is on mass participation; it is primarily designed to popularize rhythmic gymnastics among girls of different ages, from preschool to higher education.

Most authors (Siatras, Skaperda, \& Mameletzi, 2009; Vandorpe, et al., 2011; Zuniga, et al., 2011) agree that, in aesthetic sports, motor abilities are an important factor in performance improvement and in differentiation between elite and sub-elite athletes. Nowadays, top sports results are achieved by athletes who are selected in due time and who are remarkably talented and optimally prepared. Therefore, a high-quality talent identification and 
optimally planned, programmed and monitored training process are indispensable in elite athletes' development. Model values of elite gymnasts may facilitate that process.

In regard to an exceptional complexity of rhythmic gymnastics, coordination has been the most frequently tested motor ability. Vandorpe et al. (2011) examined the relationship between level of performance and motor ability test results, with a sample of 168 gymnasts (divided into two groups: elite and sub-elite). Results showed that the elite group of gymnasts surpassed the sub-elite group in all motor abilities. Purenović-Ivanović, Popović, Stanković, and Bubanj (2016) studied the possibility of predicting success in rhythmic gymnastics on the basis of the whole body coordination and concluded that the prediction was possible only in younger age categories. Douda, Toubekis, Avloniti, and Tokmakidis (2008) have concluded that the most significant determinants of success in rhythmic gymnastics are selected anthropometric characteristics, cardiovascular endurance, flexibility and explosive strength. Therefore, these crucial features should be implemented in the processes of talent identification and selection in RG.

The inspection of previous research has revealed that the most significant motor abilities are strength (Srhoj, 1989); coordination (Kioumourtzoglou, Derri, Mertzanidou, \& Tzetzis, 1997; RutowskaKucliarska \& Bober, 1998); rhythmic coordination (Miletić, Katić, \& Maleš, 2004; Persicshini, et al., 1998); flexibility (Miletić, et al., 2004), and simple movement frequency (Miletić, et al., 2004). Due to the above-mentioned results, tests for the evaluation of these motor abilities were utilised in this research.

It is necessary to determine specific tests to evaluate the state of motor abilities necessary for the highest level of competition. In that way, the process of determining in which category a gymnast should compete would be more objective. The currently valid FIG Code of Points (FIG, 2017) set a high standard, according to which only athletes with a very high level of relevant motor abilities can compete in program A. However, it is necessary to determine values of motor abilities' parameters appropriate for level program B as well, which should facilitate primary selection process and talent identification for rhythmic gymnastics, and in that way help improving the quality of rhythmic gymnasts in Croatia.

Therefore, the aim of this research was twofold: to examine the current motor status of the Croatian junior gymnasts and, based on the obtained results in motor abilities tests, to define motor abilities' model values appropriate to talent identification and orientation of gymnasts to a particular level of the $\operatorname{program}(\mathrm{A}, \mathrm{B}$, or $\mathrm{C})$ in relation to their age and the rank in the national competition.

\section{Methods}

\section{Sample of participants}

The crosssectional research included 55 junior rhythmic gymnasts (age 13-15 years), registered in the Republic of Croatia, who were divided into three groups according to the program they were competing in. The biological age of the subjects was determined by calculating the time (months) that had elapsed from the year of the first menstruation (menarche) to the date of the testing. Gymnasts were assigned to individual programs by their coaches, based on the rules prescribed by the International Gymnastics Federation (FIG, 2017). The rulebook defines the difficulties that a gymnast must adopt in order to be A or B, respectively. As stated in the rulebook, the differences between gymnasts $\mathrm{A}$ and $\mathrm{B}$ are quite small, i.e. a similar level of motor abilities is expected for both groups. As explained in the introduction, program $\mathrm{C}$ is a recreational level, or rather serves to popularize rhythmic gymnastics. The sample inclusion requirement was a minimum of five years experience in rhythmic gymnastics. The first group consisted of A-level program gymnasts $(\mathrm{n} 1=15)$, the second of B-level program gymnasts $(\mathrm{n} 2=20)$ and the third of $C$-level program rhythmic gymnasts $(n 3=20)$. In order to describe the sample of participants, three criterion variables (program level, age of participants, ranking) and nine tests for the assessment of motor abilities (flexibility, strength and coordination) were used. Table 1 shows anthropometric characteristics of the total sample, which was measured in a previous study with the same sample (Radaš, Furjan-Mandić, \& Gruić, 2018). In the same study, prevailing somatotypes of the gymnasts were determined: A-level program gymnasts were found to be of ectomorph constitution. Rhythmic gymnasts of B-level

Table 1. Descriptive statistical parameters of anthropometric variables of the Croatian junior rhythmic gymnasts

\begin{tabular}{lcccccccc}
\hline Variables & N & R & Min & Max & Mean & SD & Skew & Kurt \\
\hline AMT $(\mathbf{k g})$ & 55 & 31 & 31 & 62 & 48.20 & 8.28 & -0.29 & -0.86 \\
AVT $(\mathbf{c m})$ & 55 & 32 & 142 & 174 & 160.18 & 6.69 & -0.37 & 0.05 \\
BMI $\left(\mathbf{k g} / \mathbf{m}^{2}\right)$ & 55 & 10 & 14 & 24 & 18.58 & 2.30 & 0.29 & -0.52 \\
\hline
\end{tabular}

Note. $\mathrm{N}$ - number of participants, $\mathrm{R}$ - range, Min. - minimum value, Max. - maximum value, Mean - arithmetic mean, SD - standard deviation, Skew - coefficient of asymmetry, Kurt - coefficient of peakedness, AMT - body mass, AVT - body height, BMI - body mass index. 
program had mostly meso-ectomorph constitution, meaning that the ectomorph is the primary base of the type, followed by the mesomorphy. In athletes of C-level program, all three types of body constitution were approximately equally present (Radaš, et al., 2018).

The research was approved by the Ethical Committee of the Faculty of Kinesiology, University of Zagreb. All participants as well as their parents filled out and signed a form which was composed according to the principles of the Declaration of Helsinki, thus representing an informed consent form of participation in the research.

\section{Tests}

Tests used for the evaluation of motor abilities were chosen on the basis of results of previous research on rhythmic gymnastics, with the rationale that strength (Douda, et al., 2008; Hume, et al., 1993), coordination (Miletić, et al., 2004), and flexibility (Douda, Tokmakidis, \& Nikolaidis, 2000; Miletić \& Kostić, 2006) were considered the most important motor abilities. The tests used in this research, not specific to rhythmic gymnastics, were generally well known, to the participants and general school population alike. The tests have been used in other studies, which makes it easier to compare the results.

All the tests used for the evaluation of basic motor abilities were performed according to the standardised measuring procedures (Metikoš, Prot, Hofman, Pintar, \& Oreb, 1989). The following tests were used to evaluate athletes in this research - to evaluate flexibility: shoulder circumduction test, inverted wall straddle abduction, forward bent on the bench; to evaluate coordination: figure of eight with bending, obstacle course backwards, agility on the ground; and to evaluate leg explosive strength: broad jump, vertical jump and $20 \mathrm{~m}$ sprint from a standing start.

Shoulder circumduction test: The examinee holds a stick in front of the body standing still with the feet shoulder width apart. The task is to move the stick to the rear of the body by moving it above the head with the minimum possible distance between the hands, while keeping the arms straight. The test is performed three times in a row. Results are observed as the distance between the inner edges of the fists after the shoulders have been turned around, measured in centimeters.

Inverted wall straddle abduction: The examinee starts from a supine lying position on the mat, with the fully extended legs joined and raised up against the wall so to form a 90-degree angle with the torso. Then a maximum straddle split is performed on the wall and held until the angle between the starting and the final leg position is measured in degrees, for each leg separately. The task is repeated three times with short breaks between the executions, which are enough to perform measurements and record the measured data. Results are observed as the number of angles expressed in degrees that the examinee achieved with maximal straddle, for each leg separately, which are added to each other.

Forward bent on the bench. The examinee stands with both feet on the bench with the toes positioned on the bench edge. Legs are fully extended. The task is to deeply bend the trunk forward, while keeping the arms straight above the head and legs straight. Palms of the stretched hands "slide" down the meter scale to the lowest point possible and that position is held for a brief moment. The task is executed three times with short breaks between the executions, which are enough to perform measurements and record the measured data. Results are observed as the reach length in centimeters and each execution is noted individually.

Figure of eight with bending. On the agreed signal, the examinee circles around two stands on the polygon as fast as possible, following an imaginary line of number 8 and bending below a stretched elastic tape. When the described process has been repeated four times (eight bents below the tape) and when the examinee has passed the starting stand, the task is finished.

Obstacle course backwards. The examinee starts from the push-up position on all fours, flexed, in front of the starting line, with the back towards the course. On the starting signal, the examinee tries to overcome the $10 \mathrm{~m}$-long polygon with obstacles on all fours as fast as possible. The first obstacle is overcome by climbing over and the second one by crawling through the box. The head must never be turned in the moving direction. The task is finished when the examinee has crossed the finish line with both hands.

Agility on the ground. The examinee starts with the body fully extended in a prone position with the stretched arms raised. On the signal "Now!", the examinee rolls transversally over the three exercise mats. When the whole body has reached the fourth exercise mat, the examinee assumes a position on all fours and moves backwards in that position over the fourth mat towards the kimono. The examinee then clasps the kimono with the knees without any help from the hands (without turning) and returns on all fours towards the third exercise mat (kimono is between the legs). Backward rolls are then performed from the third to the first exercise mat. The task is finished when the examinee has passed the edge of the last exercise mat with any body part, after all the tasks have been executed correctly.

Broad jump. The task is performed so that the examinee assumes a position on the front edge of a springboard, facing the exercise mats. A two-feet take-off is performed (with a free arm swing) and the examinee jumps as far as possible. 
Vertical jump. The examinee places the arm which is closer to the wall into an overhead position and places the hand on the wall with the stretched fingers. The task is to take-off vertically with maximum strength and to touch the wall in the highest point of the jump.

$20 \mathrm{~m}$ sprint from a standing start: The examinee sprints between the start and finish lines as fast as possible, on the mark "Get ready!" followed by a stick clap. The task is finished when the examinee has crossed the finish line with the chest. It is executed three times with a break between every run.

\section{Statistical analysis}

Basic descriptive parameters were calculated for all the variables, and distribution normality was tested with the Kolmogorov-Smirnov test. The differences in motor abilities' values with respect to biological age, program level, and ranking were determined using multivariate analysis of variance (MANOVA), while the univariate analysis of variance (ANOVA) was used to determine partial changes for each variable. The relationships between the investigated motor abilities and each program was determined by the Pearson correlation coefficient.

\section{Results}

Table 2 displays descriptive parameters of the results in motor tests achieved by the junior rhythmic gymnasts of the Republic of Croatia.

Multivariate analysis confirmed that, on a global level, there were statistically significant differences between junior rhythmic gymnasts with regard to their biological and program level (Table 3), so we could conclude that the coaches had made a good selection of the gymnasts for each category.

The partial differences in motor abilities of the junior rhythmic gymnasts of the Republic of Croatia in relation with their competition ranking, showed no statistical significance in any of the tests (Table 4).

Univariate analysis of variance (ANOVA) revealed statistically significant differences in all tests of motor abilities with regard to program level (A, B, or C). On the basis of the results acquired with univariate analysis of variance, in almost all motor tests there were statistically significant differences between the examinees with regard to program level (Table 5).

The results of correlation analysis between motor variables of rhythmic gymnasts of $A, B$ and $\mathrm{C}$ program level have been determined with the level of significance of $95 \%$ and are shown in Tables

Table 2. Descriptive statistical parameters of the scores on motor tests achieved by the Croatian junior rhythmic gymnasts

\begin{tabular}{lcccccccc}
\hline Tests & N & R & Min & Max & Mean & SD & Skew & Kurt \\
\hline MFLISK (cm) & 55 & 76 & 0 & 76 & 35.62 & 18.41 & 0.13 & -0.25 \\
MFLRLK ( ${ }^{\circ}$ ) & 55 & 70 & 120 & 190 & 163.64 & 14.42 & -0.31 & 0.55 \\
MFLPRK (cm) & 55 & 28 & 7 & 35 & 22.22 & 6.48 & -0.12 & -0.51 \\
MAGOSS (s) & 55 & 5 & 17 & 22 & 18.58 & 1.13 & 0.66 & 0.49 \\
MREPOL (s) & 55 & 7 & 6 & 13 & 9.47 & 1.41 & 0.65 & 0.99 \\
MAGONT (s) & 55 & 4 & 6 & 10 & 7.89 & 0.92 & 0.52 & -0.24 \\
MFESDM (cm) & 55 & 57 & 147 & 204 & 178.51 & 14.20 & 0.23 & -0.67 \\
MFESVM (cm) & 55 & 25 & 25 & 50 & 37.73 & 6.36 & -0.02 & -0.72 \\
MFE2OV (s) & 55 & 1 & 4 & 5 & 4.11 & 0.31 & 2.58 & 4.82 \\
\hline
\end{tabular}

Note. N - number of participants, R - range, Min - minimum, Max - maximum, Mean - arithmetic mean, SD - standard deviation, Skew - coefficient of asymmetry, Kurt - coefficient of peakedness, MFLISK - shoulder circumduction test, MFLRLK - maximal inverted wall straddle abduction, MFLPRK - forward bent on the bench, MAGOSS - figure of eight with bending, MREPOL - obstacle course backwards, MAGONT - agility on the ground, MFESDM - broad jump, MFESVM - vertical jump, MFE20V - 20 m sprint from a standing start.

Table 3. Multivariate differences in morphological characteristics and motor abilities of rhythmic gymnasts regarding their ranking, biological age and program level

\begin{tabular}{lccc}
\hline Variables & Wilks'Lambda & $\mathbf{F}$ & $\mathbf{p}$ \\
\hline RANKING & .82 & .71 & .73 \\
BIOLOGICAL AGE & .50 & 3.32 & .00 \\
PROGRAM & .21 & 3.93 & .00 \\
\hline
\end{tabular}

Note. Wilks'Lambda - Wilks'Lambda value, F - approximal F-value, $p$ - error, RANKING - ranking in the competition, PROGRAM - A, B or C rhythmic gymnastic program.
$6 \mathrm{a}, 6 \mathrm{~b}$ and $6 \mathrm{c}$. According to a rough approximation of correlation level between two variables (Petz, 2004), it is possible to determine that the values of correlation coefficient $r$ from 0.00 to \pm 0.20 mean no correlation or an insignificant one, the values of correlation coefficient $r$ from \pm 0.20 to \pm 0.40 mean a light correlation, while the values of correlation coefficient $r$ from $\pm 0,40$ to $\pm 0,60$ mean a high correlation.

The results of the present research gave the means to the authors to extrapolate model values 
Table 4. Partial differences, acquired with ANOVA, in motor abilities of the Croatian junior rhythmic gymnasts regarding their competition ranking, biological age and program level

\begin{tabular}{|c|c|c|c|}
\hline & Variables & $\mathbf{F}$ & $p$ \\
\hline \multirow{9}{*}{ Ranking } & MFLISK (cm) & 0.16 & 0.70 \\
\hline & $\operatorname{MFLRLK}\left({ }^{\circ}\right)$ & 0.50 & 0.48 \\
\hline & MFLPRK $(\mathrm{cm})$ & 0.05 & 0.83 \\
\hline & MAGOSS (s) & 1.41 & 0.24 \\
\hline & MREPOL (s) & 0.85 & 0.36 \\
\hline & MAGONT (s) & 2.77 & 0.10 \\
\hline & MFESDM $(\mathrm{cm})$ & 0.11 & 0.75 \\
\hline & MFESVM (cm) & 0.03 & 0.87 \\
\hline & MFE20V (s) & 0.62 & 0.43 \\
\hline \multirow{9}{*}{$\begin{array}{l}\text { Biological } \\
\text { age }\end{array}$} & MFLISK $(\mathrm{cm})$ & 0.29 & 0.59 \\
\hline & $\operatorname{MFLRLK}\left({ }^{\circ}\right)$ & 2.80 & 0.10 \\
\hline & MFLPRK $(\mathrm{cm})$ & 4.07 & 0.05 \\
\hline & MAGOSS (s) & 0.01 & 0.93 \\
\hline & MREPOL (s) & 0.35 & 0.56 \\
\hline & MAGONT (s) & 0.28 & 0.60 \\
\hline & MFESDM $(\mathrm{cm})$ & 0.29 & 0.59 \\
\hline & MFESVM (cm) & 2.18 & 0.15 \\
\hline & MFE20V (s) & 0.92 & 0.34 \\
\hline \multirow{9}{*}{ Program } & MFLISK (cm) & 6.40 & 0.00 \\
\hline & $\operatorname{MFLRLK}\left({ }^{\circ}\right)$ & 14.00 & 0.00 \\
\hline & $\operatorname{MFLPRK}(\mathrm{cm})$ & 8.91 & 0.00 \\
\hline & MAGOSS (s) & 10.43 & 0.00 \\
\hline & MREPOL (s) & 14.68 & 0.00 \\
\hline & MAGONT (s) & 3.49 & 0.04 \\
\hline & MFESDM $(\mathrm{cm})$ & 4.06 & 0.02 \\
\hline & MFESVM (cm) & 9.07 & 0.00 \\
\hline & MFE20V (s) & 5.93 & 0.01 \\
\hline
\end{tabular}

Note. F - ANOVA value, MFLISK - shoulder circumduction test, MFLRLK - maximal inverted wall straddle abduction, MFLPRK - forward bent on the bench, MAGOSS - figure of eight with bending, MREPOL - obstacle course backwards, MAGONT - agility on the ground, MFESDM - broad jump, MFESVM vertical jump, MFE20V - $20 \mathrm{~m}$ sprint from a standing start. for the future RG talent identification and selection purposes, at least in the Republic of Croatia.

\section{Discussion and conclusion}

The goal of this research was to define the actual state of the Croatian junior rhythmic gymnasts on the basis of basic motor abilities tests with regard to program level (A, B, C), biological age and ranking in the national competition. Statistically significant differences were established in motor abilities between rhythmic gymnasts of A, B and C program level as well as with regard to biological age. The

Table 5. Differences in motor variables between rhythmic gymnasts of the Republic of Croatia in regard to $A, B$ and $C$ program, acquired with ANOVA

\begin{tabular}{|c|c|c|c|c|c|}
\hline \multicolumn{3}{|c|}{ Dependent variables } & \multirow{2}{*}{$\begin{array}{c}\begin{array}{c}\text { Mean } \\
\text { difference }\end{array} \\
9.33\end{array}$} & \multirow{2}{*}{$\begin{array}{c}\begin{array}{c}\text { Std. } \\
\text { error }\end{array} \\
4.58\end{array}$} & \multirow{2}{*}{$\begin{array}{c}\mathbf{p} \\
.14\end{array}$} \\
\hline \multirow{6}{*}{$\begin{array}{l}\text { MFESDM } \\
\text { (cm) }\end{array}$} & \multirow{2}{*}{ A } & B & & & \\
\hline & & C & $13.28^{*}$ & 4.58 & .02 \\
\hline & \multirow{2}{*}{ B } & A & -9.33 & 4.58 & .14 \\
\hline & & C & 3.95 & 4.24 & 1.00 \\
\hline & \multirow{2}{*}{ C } & A & $-13.28^{*}$ & 4.58 & .02 \\
\hline & & B & -3.95 & 4.24 & 1.00 \\
\hline \multirow{6}{*}{$\begin{array}{l}\text { MFESVM } \\
\text { (cm) }\end{array}$} & \multirow{2}{*}{ A } & B & 2.70 & 1.84 & .44 \\
\hline & & C & $8.50^{*}$ & 1.84 & .00 \\
\hline & \multirow{2}{*}{ B } & A & -2.70 & 1.84 & .44 \\
\hline & & C & $5.80^{*}$ & 1.70 & .00 \\
\hline & \multirow{2}{*}{ C } & A & $-8.50^{*}$ & 1.84 & .00 \\
\hline & & B & $-5.80^{*}$ & 1.70 & .00 \\
\hline \multirow{6}{*}{$\begin{array}{l}\text { MFE20V } \\
\text { (s) }\end{array}$} & \multirow{2}{*}{ A } & B & 0,00 & . 0 & 1.00 \\
\hline & & C & $-.30^{*}$ & .10 & .01 \\
\hline & \multirow{2}{*}{ B } & A & 0.00 & .10 & 1.00 \\
\hline & & C & $-.30^{*}$ & .09 & .01 \\
\hline & \multirow{2}{*}{ C } & A & $.30^{*}$ & .10 & .01 \\
\hline & & B & $.30^{*}$ & .09 & .00 \\
\hline
\end{tabular}

Table 6a. Correlation between motor variables of the Croatian junior rhythmic gymnasts of A program - Pearson correlation coefficient

\begin{tabular}{|c|c|c|c|c|c|c|c|c|c|}
\hline Variables & MFLISK & MFLRLK & MFLPRK & MAGOSS & MREPOL & MAGONT & MFESDM & MFESVM & MFE20V \\
\hline MFLISK (cm) & 1 & & & & & & & & \\
\hline $\operatorname{MFLRLK}\left({ }^{\circ}\right)$ & -.593 & 1 & & & & & & & \\
\hline MFLPRK (cm) & -.435 & .124 & 1 & & & & & & \\
\hline MAGOSS (s) & .439 & -.576 & .168 & 1 & & & & & \\
\hline MREPOL (s) & .394 & -.599 & .096 & .397 & 1 & & & & \\
\hline MAGONT (s) & .380 & -.244 & -.516 & .054 & -.149 & 1 & & & \\
\hline MFESDM (cm) & -.526 & .333 & .421 & -.528 & -.287 & -.364 & 1 & & \\
\hline MFESVM (cm) & -.495 & -.032 & .475 & -.510 & -.080 & -.268 & .730 & 1 & \\
\hline MFE20V (s) & .284 & -.013 & .103 & .087 & .486 & .093 & -.607 & .558 & 1 \\
\hline
\end{tabular}

Note. MFLISK - shoulder circumduction test, MFLRLK - maximal inverted wall straddle abduction, MFLPRK - forward bent on the bench, MAGOSS - figure of eight with bending, MREPOL - obstacle course backwards, MAGONT - agility on the ground, MFESDM - broad jump, MFESVM - vertical jump, MFE20V - 20 m sprint from a standing start. 
Table 6b. Correlation between motor variables of junior rhythmic gymnasts of B program of Republic of Croatia - Pearson correlation coefficient

\begin{tabular}{|c|c|c|c|c|c|c|c|c|c|}
\hline Variables & MFLISK & MFLRLK & MFLPRK & MAGOSS & MREPOL & MAGONT & MFESDM & MFESVM & MFE20V \\
\hline MFLISK (cm) & 1 & & & & & & & & \\
\hline $\operatorname{MFLRLK}\left({ }^{\circ}\right)$ & .027 & 1 & & & & & & & \\
\hline MFLPRK (cm) & .101 & -.095 & 1 & & & & & & \\
\hline MAGOSS (s) & -.301 & .339 & -.029 & 1 & & & & & \\
\hline MREPOL (s) & .007 & .215 & .448 & .430 & 1 & & & & \\
\hline MAGONT (s) & .060 & .071 & .118 & .452 & .429 & 1 & & & \\
\hline MFESDM (cm) & .017 & -.196 & .068 & -.409 & -.118 & -.090 & 1 & & \\
\hline MFESVM (cm) & .320 & .021 & .323 & -.286 & .024 & -.114 & .730 & 1 & \\
\hline MFE20V (s) & -0.091 & 0.076 & 0.156 & 0.48 & 0.419 & 0.607 & -0.644 & -0.61 & 1 \\
\hline
\end{tabular}

Note. AMT - body mass, AVT - body height, AITM - body mass index, MFLISK - shoulder circumduction test, MFLRLK - maximal inverted wall straddle abduction, MFLPRK - forward bent on the bench, MAGOSS - figure of eight with bending, MREPOL - obstacle course backwards, MAGONT - agility on the ground, MFESDM - broad jump, MFESVM - vertical jump, MFE20V - $20 \mathrm{~m}$ sprint from a standing start.

Table 6c. Correlation between motor variables of junior rhythmic gymnasts of C program of Republic of Croatia - Pearson correlation coefficient

\begin{tabular}{|c|c|c|c|c|c|c|c|c|c|}
\hline Variables & MFLISK & MFLRLK & MFLPRK & MAGOSS & MREPOL & MAGONT & MFESDM & MFESVM & MFE20V \\
\hline MFLISK (cm) & 1 & & & & & & & & \\
\hline MFLRLK $\left({ }^{\circ}\right)$ & -.241 & 1 & & & & & & & \\
\hline MFLPRK (cm) & -.527 & .032 & 1 & & & & & & \\
\hline MAGOSS (s) & -.079 & -.099 & -.439 & 1 & & & & & \\
\hline MREPOL (s) & .263 & .252 & -.513 & .307 & 1 & & & & \\
\hline MAGONT (s) & -.066 & .511 & -.100 & .121 & .471 & 1 & & & \\
\hline MFESDM (cm) & -.093 & -.372 & .218 & -.180 & -.526 & -.501 & 1 & & \\
\hline MFESVM (cm) & -.209 & -.071 & .368 & -.177 & -.072 & -.162 & .452 & 1 & \\
\hline MFE20V (s) & .013 & .599 & -.255 & .164 & .201 & .329 & -.401 & -.158 & 1 \\
\hline
\end{tabular}

Note. MFLISK - shoulder circumduction test, MFLRLK - maximal inverted wall straddle abduction, MFLPRK - bench bending, MAGOSS - figure of eight with bending, MREPOL - obstacle course backwards, MAGONT - agility on the ground, MFESDM - broad jump, MFESVM - vertical jump, MFE2OV - 20 m sprint from a standing start.

Table 7a. Flexibility tests' model values of the Croatian junior rhythmic gymnasts executing A program

\begin{tabular}{lccc}
\hline & $\begin{array}{c}\text { MFLISK } \\
(\mathbf{c m})\end{array}$ & $\begin{array}{c}\text { MFLRLK } \\
\left({ }^{\circ}\right)\end{array}$ & $\begin{array}{c}\text { MFLPRK } \\
(\mathbf{c m})\end{array}$ \\
\hline Above average & 7.35 & 186.78 & 31.72 \\
Average & 23.82 & 177 & 26.96 \\
Below average & 40.29 & 167.22 & 22.20 \\
\hline
\end{tabular}

Note. MFLISK - shoulder circumduction test, MFLRLK maximal inverted wall straddle abduction, MFLPRK - forward bent on the bench.

Table 7b. Coordination tests' model values of the Croatian junior rhythmic gymnasts executing A program

\begin{tabular}{lccc}
\hline & $\begin{array}{c}\text { MAGOSS } \\
\text { (s) }\end{array}$ & $\begin{array}{c}\text { MREPOL } \\
\text { (s) }\end{array}$ & $\begin{array}{c}\text { MAGONT } \\
\text { (s) }\end{array}$ \\
\hline Above average & 16.97 & 7.45 & 6.60 \\
Average & 17.79 & 8.38 & 7.51 \\
Below average & 18.61 & 9.31 & 8.42 \\
\hline
\end{tabular}

Note. MAGOSS - figure of eight with bending, MREPOL obstacle course backwards, MAGONT - agility on the ground.
Table 7c. Strength tests' model values of the Croatian junior rhythmic gymnasts executing A program

\begin{tabular}{lccc}
\hline & $\begin{array}{c}\text { MFESDM } \\
\text { (cm) }\end{array}$ & $\begin{array}{c}\text { MFESVM } \\
\text { (cm) }\end{array}$ & $\begin{array}{c}\text { MFE20V } \\
\text { (s) }\end{array}$ \\
\hline Above average & 201.20 & 47.27 & 3.98 \\
Average & 186.72 & 41.82 & 4.15 \\
Below average & 172.24 & 36.37 & 4.32 \\
\hline
\end{tabular}

Note. MFESDM - broad jump, MFESVM - vertical jump, MFE20V - $20 \mathrm{~m}$ sprint from a standing start.

correlation of motor abilities and ranking in the national competition was not established.

The results indicate that there are differences in flexibility, coordination and strength between rhythmic gymnasts of different program levels, and that rhythmic gymnasts of program A scored better than the gymnasts of program B and especially than the gymnasts of program $C$. The results are in accordance with the research conducted by Douda et al. $(2000,2008)$, which indicated that 
flexibility, explosive leg strength and coordination were the most significant determinants of success in rhythmic gymnastics, and that these findings were crucial for selection in that sport.

Generally, the statistically significant differences were determined in all flexibility tests between the highest standard program level (A program) and the lowest standard program level (C program). The determined differences were anticipated because a high level of flexibility of all joint structures is expected from the examinees of program A, which enables them to execute the most difficult elements regulated by the rulebook of the International Gymnastics Federation (FIG). For the gymnasts of program $\mathrm{C}$, difficulty requirements are much lower, and gymnasts with just an optimal flexibility can execute a specific task that is expected from them. Furthermore, from the gymnasts of program level $\mathrm{B}$ it is expected to eventually cross into program $\mathrm{A}$, observable in difficulty requirements and the score, which is by only one point lower than the final score of gymnasts of program A. This is confirmed with our results, where junior rhythmic gymnasts of program A and B demonstrated approximately equal mobility of the measured joint structures.

Also, a statistically significant difference was determined between rhythmic gymnasts of different program levels in all explosive strength tests. Statistically significant differences were determined between $\mathrm{A}$ and $\mathrm{C}$, and $\mathrm{B}$ and $\mathrm{C}$ level gymnasts in the following tests: broad jump, vertical jump and 20-meter sprint. The results are in accordance with the results acquired by Douda et al. (2008), who have determined that explosive strength is one of the most significant determinants of success in rhythmic gymnastics. That means much time and effort should be dedicated to the development of this motor ability in the training process, especially in the gymnasts of a higher program level. In all the tests, the largest differences were obtained between programs A and C. Furthermore, there were no significant differences between gymnasts of programs $B$ and $C$. This is not surprising given the similarities in the difficulty requirements between programs $\mathrm{A}$ and $\mathrm{B}$. By the univariate analysis, the largest differences between the A and B program gymnasts were found in the maximal inverted wall straddle abduction, whereas in all the other tests no significant differences were established between the A and B program. Such a finding can be justified by a very small scoring difference between the two programs. On the basis of the analyzed results, it should be noted that the Croatian junior rhythmic gymnasts considerably differ in the measuered motor abilities with regard to biological age and program level; however, the highest differences were determined between rhythmic gymnasts of $\mathrm{A}$ and $\mathrm{C}$ program levels.

This research findings are supported by the research conducted by Miletić et al. (2004), who suggested that the training process in rhythmic gymnastics must be programmed with the goal of developing flexibility and explosive strength, while subcutaneous fatty tissue should be reduced. These three factors explain around $50 \%$ of the variance of good performance of body elements and elements with apparatuses in rhythmic gymnastics. When the correlation coefficients between motor variables are observed, we can see that all the variables are in high correlation. That was expected, because, for a rhy thmic gymnast to perform best as possible and to get closer to the elite level, an equally high level of the observed motor abilities (flexibility, coordination, strength) is expected. Kioumourtzoglou et al. (1997) and Vandorpe et al. (2011) have determined that the elite group of gymnasts surpasses the sub-elite group in all motor abilities. Correlations between motor variables were lower in program $B$ than in program $A$, which had been expected, because motor abilities of the program B gymnasts were weaker, therefore the correlation coefficients between the observed variables were lower. It was expected that correlation values would be the lowest in program $\mathrm{C}$, which was confirmed in this research.

According to the analyzed results in motor tests, we presented (Tables $7 \mathrm{a}, 7 \mathrm{~b}$, and 7c) model values of the motor abilities' testing scores of the Croatian junior rhythmic gymnasts that were, in fact, the scores achieved by the gymnasts of program A. Other researchers and gymnastic practitioners may use them for various comparisons.

Such model values will contribute to improvements of training planning, programming and control since they enable comparisons with world class rhythmic gymnasts, thus pointing out weaknesses and strengths of Croatian gymnasts. The findings of our study may help coaches in planning gymnasts' transfer onto a higher program level and in selecting the best rhythmic gymnasts for the national team. Furthermore, this paper should enable a talent identification and selection process of a higher quality, intra- and inter-group comparisons between the Croatian and world class junior rhythmic gymnasts, as well as comparisons with athletes of other aesthetic sports. 


\section{References}

Bozanic, A., \& Miletic, D. (2011). Differences between the sexes in technical mastery of rhythmic gymnastics. Journal of Sports Sciences, 29(4), 337-343.

Di Cagno, A., Baldari, C., Battaglia, C., Monteiro, M.D., Pappalardo, A., Piazza, M., \& Guidetti, L. (2009). Factors influencing performance of competitive and amateur rhythmic gymnastics - Gender differences. Journal of Science and Medicine in Sport, 12(3), 411-416.

Di Cagno, A., Battaglia, C., Fiorilli, G., Piazza, M., Giombini, A., Fagnani, F., . . , \& Pigozzi, F. (2014). Motor learning as young gymnast's talent indicator. Journal of Sports Science and Medicine,13(4), 767.

Douda, H.T, Tokmakidis, S., \& Nikolaidis, K. (2000). Kinanthropometric characteristics and physical fitness attributes as predictors of attainment in rhythmic sports gymnastics. Journal of Sports Sciences, 15(1), 70-71.

Douda, H.T., Toubekis, A.G., Avloniti, A.A., \& Tokmakidis, S.P. (2008). Physiological and anthropometric determinants of rhythmic gymnastics performance. International Journal of Sports Physiology and Performance, 3(1), 41-54.

FIG - Fédération Internationale de Gymnastique. (2017). General judges’ rules 2017-2020. Retrieved on April 18, 2019 from: https:/www.gymnastics.sport/publicdir/rules/files/en_RG\%20CoP\%202017-2020\%20with\%20 Errata\%20Dec.\%2017.pdf

Hume, P., Hopkins, W., Robinson, D., Robinson, S., \& Hollings, S. (1993). Predictors of attainment in rhythmic sportive gymnastics. Journal of Sports Medicine and Physical Fitness, 33, 367-377.

Jastrjembskaia, N., \& Titov, Y. (1999). Rhythmic gymnastics. Champaign, IL: Human Kinetics.

Kioumourtzoglou, E., Derri, V., Mertzanidou, O., \& Tzetzis, G. (1997). Experience with perceptual and motor skills in rhythmic gymnastics. Perceptual and Motor Skills, 84(3_Suppl), 1363-1372.

Metikoš, D., Prot, F., Hofman, E., Pintar, Ž., \& Oreb, G., (1989). Mjerenje bazičnih motoričkih dimenzija sportaša. [Measurement of athletes' basic motor dimensions. In Croatian.] Zagreb: Fakultet za fizičku kulturu Sveučilišta u Zagrebu.

Miletić, Đ., Katić, R., \& Maleš, B. (2004). Some anthropologic factors of performance in rhythmic gymnastics novices. Collegium Antropologicum, 28(2), 727-737.

Miletić, Đ., \& Kostić, R. (2006). Motor and morphological conditionality for performing arabesque and passe pivots. Facta Uuniversitatis - Series: Physical Education and Sport, 4(1), 17-25.

Persichini, C., Baldari, C., Guidetti, L., Trombetta, M., Capranica, L., \& Figura, F. (1998). Assessment of rhythmic ability: Differences between sedentary and rhythmic gymnastic athletes. Journal of Sports Sciences, 16(5), 397-398.

Petz, B. (2002). Osnovne statističke metode za nematematičare (4th ${ }^{\text {th }}$ ed.). [Basic statistical methods for non-mathematicians. In Croatian.] Jastrebarsko: Naklada Slap.

Purenović-Ivanović, T.M., Popović, R., Stanković, D., \& Bubanj, S. (2016). The importance of motor coordination abilities for performance in rhythmic gymnastics. Facta Universitatis - Series: Physical Education and Sport, 14(1), 63-74.

Radaš, J., Furjan-Mandić, G., \& Gruić, I. (2018). Anthropometrical characteristics and somatotype of junior rhythmic gymnasts of Republic of Croatia. In P. Pezarat-Correia, J.P Vilas-Boas, O. Rivera \& J. Cabri (Eds.), Proceedings of the $6^{\text {th }}$ International Congress on Sport Sciences Research and Technology Support (icSPORTS 2018) (pp. 165-169). Sevilla, Spain.

Rutowska-Kucharska, A., \& Bober, T. (1998). Cordination of arms swing and take-off in rhythmic sportive gymnastics jumps. In A.J. Sargeant \& H. Siddons (Eds.), Third ECSS Proceedings Book (p. 30), Manchester, UK.

Siatras, T., Skaperda, M., \& Mameletzi, D. (2009). Anthropometric characteristics and delayed growth in young artistic gymnasts. Medical Problems of Performing Artists, 24(2), 91.

Srhoj, Lj. (1989). Relacije između nekih antropometrijskih, motoričkih i funkcionalnih manifestnih i latentnih dimenzija učenica i uspjeha u ritmičko-športskoj gimnastici. [Relations between some anthropometric, motor and functional manifest and latent dimensions of female students and success in rhythmic gymnastics. In Croatian.] (Doctoral dissertation, University in Skopje). Skopje: Fakultet za fizičku kulturu Sveučilišta u Skopju.

Vandorpe, B., Vandendriessche, J., Vaeyens, R., Pion, J., Lefevre, J., Philippaerts, R., \& Lenoir, M. (2011). Factors discriminating gymnasts by competitive level. International Journal of Sports Medicine, 32(08), 591-597.

Zuniga, J., Housh, T.J., Camic, C.L., Mielke, M., Hendrix, C.R., Johnson, G.O., . . . , \& Schmidt, R.J. (2011). Yearly changes in the anthropometric dimensions of female high school gymnasts. Journal of Strength and Conditioning Research, 25(1), 124-128.

Submitted: May 17, 2019

Accepted: June 21, 2019

Published Online First: November 15, 2019
Correspondence to:

Josipa Radaš, Ph.D.

University of Zagreb, Faculty of Kinesiology, Croatia

E-mail: josipa.radas@kif.hr 